\title{
Perspectives
}

\section{The Management of Time Lapses in Conventional Communicative Approaches}

\author{
Anthony Bruton
}

It is argued that the sensitive management of time lapses or timing should be an important part of conventional communicative approaches in the L2 classroom. Distinctions must be made between timing and silence and between different types of teacher-managed time lapses. Suggestions for classroom application are drawn from a wide range of current theoretical and research perspectives.

The purpose of this article is to isolate the factors that affect timing in conventional communicative classrooms, to summarize research evidence on the significance of timing, and to identify some of the contexts where timing should be a consideration.

\section{Some Empirical Evidence}

The empirical evidence on timing in L2 learning is limited. Let us assume that the learner usually has to process a language cue, retrieve information, and formulate a response that is then to be articulated. A typical routine might include a teacher's question requiring the understanding of a text and a learner response. In such cases, Holley and King (1971) found that teachers generally cut short learner hesitations or incorrect responses. Similarly, van Lier (1988) concluded that teachers are often too hasty in their interventions, not allowing learners time to self-correct or rephrase what they have said. White and Lightbown (1984) found that the average wait time was around 2.1 seconds, a finding similar to Rowe's L1 results (1987). Shrum and Tech (1985) observed target L2 language wait times to average around 1.9 seconds, shorter than the L1 time of 2.3 seconds. The L2 and L1 postresponse wait times (Rowe's wait time 2) were both 0.7 seconds, with some variation according to the task.

When wait times are increased there are numerous benefits to both teachers and learners. Rowe (1987) found that teachers become more flexible and ask fewer questions; moreover, the questions they ask tend to be more relevant and interesting. She lists the following benefits for learners: longer responses, use of more supporting evidence, more speculation, more questions, fewer response failures, more peer exchanges, greater variety of par- 
ticipation, more confidence, and greater achievement. Holley and King (1971) point out that silence takes up less time than rephrasing, correcting, and explaining. Ellis (1987) showed that having more time results in greater accuracy in the production of regular past tense forms, and Crookes (1989) noted that learners use a wider variety of language when they are given sufficient time.

\section{Being Silent and Having Time to Think}

We consider three factors that affect having time to process language. These are types of response, contributors in the classroom, and length of time lapses in interactions. We can differentiate between conspicuous verbal and nonverbal responses. This distinction can explain why the mere presence of silence does not necessarily mean that a learner has time to assimilate input. In some TPR experiences, for instance, learners may be expected to respond before they have really discriminated the linguistic cues for specific physical responses.

The contributors to conspicuous classroom verbal behavior are the teacher, peers, and recorded materials. They are significant because not only are they sources of input, but they are sources of possible interference with the learner's language processing. For example, a learner might not have time to assimilate the input before a peer's intervention interrupts or puts pressure on the processing.

Teacher-controlled time lapses between the initial (focused) input and conspicuous learner action, whether verbal or nonverbal, can vary considerably. Delayed responses equate with the extended silent period advocated in the Natural Approach, for example. When a response is delayed, the learner does not manifest any immediate conspicuous response, but is expected to react later on, once the input is presumed to be internalized. Examples of this are certain TPR activities or conventional postdialogue activities. Deliberated and spontaneous time lapses refer to immediate learner silences and correspond to wait time (Rowe, 1974). The difference between them is that the deliberated lapse gives the learner additional time to think, more than would be provided to a NS, even though it may be a matter of only a few seconds.

As Carlsen (1991) rightly argues with respect to classroom questioning, one can never consider learning variables outside their context. The same applies to time lapses. Whether learners have enough time to process input depends on their knowledge and ability relative to the task and the external time pressures on its completion, especially in the public arena. The teacher should try to predict the difficulty of a given task and make appropriate processing time available. This can be achieved by managing time lapses (i.e., total silences) and input effectively in the teacher-fronted class. The assump- 
tion is that when learners have adequate time, their performance will improve (Rowe, 1987; White \& Lightbown, 1984). Of particular interest are those contexts in which spontaneous conspicuous behavior can be replaced by deliberated or delayed conspicuous behavior in order to allow more processing time. For example, routines that include wait times can be substituted for rapid-fire question-and-answer routines.

\section{The Management of Time Lapses}

The double-edged nature of silence is reflected in Dillon's (1988) distinction between deliberate and nondeliberate silences in teacher-fronted activities. Deliberate silences are positive only when they are appreciative or attentive, not stony and withdrawn. Time lapses in classroom oral activity can be categorized as follows:

1. teacher-prescribed;

2. teacher-determined;

3. teacher-class negotiated;

4. teacher-learner negotiated;

5. peer-determined.

The teacher can prescribe a time limit before a task requiring student preparation by judging its complexity. The teacher can determine the time limit by observing when the learners are ready or by asking them to look up when they have completed a prepared task. The teacher may negotiate a time limit by asking the class members whether they are ready. Alternatively, when particular learners respond, they may need time to reformulate in mid-utterance, or to self-correct (van Lier, 1988). This type of negotiation is what Rowe (1974) has called wait time 2. Finally, the teacher can leave the time limit up to the first learner who responds (i.e., calling out). In order to ensure more deliberated responses, the options that allow the greatest sensitivity for adequate time lapses are teacher-determined, teacher-class negotiated and teacher-learner negotiated.

\section{Applications in Conventional Communicative Classes}

The most obvious recommendation for conventional communicative approaches arising from research on wait time is to make more time for the learners. Once a teacher is aware of this, it is not difficult to achieve. Rowe (1987) suggests providing at least three seconds of wait time in the L1 context, and White and Lightbown (1984) from five to 10 seconds in ESL settings. This is achieved by giving clear instructions and carefully orchestrating the class. In addition to allowing more actual time, teachers can expand mental time, usually by freeing attention through planning and preparation. With this in mind, let us consider some common language classroom activities. 
In learning-focused activities for new language, learners need time to use the familiar to decipher the unfamiliar. Furthermore, to Swain (1985) it "seems much more likely that it is only when the substance of the message is understood that the learner can pay attention to the means of expression" (p. 248). Cook (1994) makes a similar claim and champions the repetition and learning by heart of form as authentic types of intimate discourse. Terrell (1986) acknowledges the time it can take to assimilate a form, even for recognition. The need for additional attention to appropriate initial storage is reflected in much of the research on key words and language mediators for vocabulary maintenance (Cohen, 1987).

Analysis should be accompanied by synthesis. If the learners are reassessing, relating, or integrating known language, they have to access the relevant knowledge, as not all knowledge is available simultaneously. Colleagues of mine have encouraged learners to explain their doubts or hypotheses, sometimes by contributing anomalous or seemingly contradictory examples for consideration. Alternatively, teachers can prepare examples for analysis, or attention to misuses, with the ultimate goal of extending the learner's interlanguage system, rather than accumulating entities (Rutherford, 1987). When appropriate input, sometimes in the form of comparable examples, is concentrated on paper, overhead transparencies, or the blackboard, generalizations and anomalies become more apparent. This type of presentation is compatible with Rutherford's (1987) proposals for consciousness-raising through tasks for reflection, including judgment, discrimination, and discernment.

Another option is to provide time for learners to introspect. Cohen (1987) distinguishes verbal reports by the proximity of the report to the event. At one extreme learners can think aloud to each other about what they are doing during a task. At the other extreme learners can keep diaries of their experience during language learning. In between are verbal reports to the teacher or peers, responses to questionnaires, or interactive questions and answers on learning. All these activities encourage reflection on learning experiences.

In phonological development, second language learners may use nonarticulatory inner speech (Murphy, 1989), subvocalization or silent practice (Catford \& Pisoni, 1970), and private speech (Saville-Troike, 1988). SavilleTroike (1988) noted that learners practice when they expect to produce language in the future. The teacher can use timing in various ways here. First, pausing after significant input can facilitate the use of the learners' short-term acoustic store for analysis (Murphy, 1989). This echoic effect may be useful for maintaining recently perceived acoustic signals. In addition, the learners can be asked to prepare speech and subvocalize it before saying it out loud. Awareness can also be achieved by describing explicitly how 
speech sounds are formed (Catford \& Pisoni, 1970), without the learners' initially vocalizing them. Having learners listen to recordings of themselves is nothing new, but with the decline in the use of language laboratories, it has become rarer. Such experience has been rewarding for students I have taught who were unaware of some of their own limitations.

Learner time can be made available in real time listening, and reading, by preparing the learners for the language, content, and context of the task (Skehan, 1993). Preferably, the task should be set initially to direct attention and to allow for a response that can be constructed during the task. Eliciting a more spontaneous response may, paradoxically, require more time. Dirven and Oakeshott-Taylor (1985) and Chaudron (1985b) suggest that more time is needed for deeper comprehension and / or for formulating responses. Logically, complex listening and reading tasks should be more decentralized into group work or pair work (White \& Lightbown, 1984), perhaps with written or visual checks that can be learner-paced. In these prepared listening or reading tasks, the postinitial-response wait times should be increased to allow for thought.

Particularly problematic is balancing authentic listening tasks with input that is sufficiently slow (Chaudron, 1985a), but that does not lose its "prosodic continuity" (Dirven \& Oakeshott-Taylor, 1984). Some available options, apart from teacher talk, are semiscripted dialogues, slow colloquial monologues from the radio or TV, authentic repetitions, such as two recordings of the same topic - perhaps one by the teacher, with additional emphasis, segmenting, and pausing; two different tasks on the same input; and authentic dictation (Dirven \& Oakeshott-Taylor, 1985).

In interactive oral activities, Willis (1990) has learners prepare oral summaries, during which time the speaker keeps the floor until the turn is completed. Oral tasks can also be rehearsed. Tarvin and Al-Arishi (1991) argue that interactive activities often suppress reflection and do not allow time for genuine hypothesis building. They insist on personal tasks and introspection before interaction. Skehan (1993) outlines the means whereby content, language, and timing can be balanced to improve correctness in communication tasks. Apart from preparatory work, the development of floor-keeping strategies, dividing information, allocating roles such as moderator, and stipulating generous time limits will make time for individual participants. Finally, Tarvin and Al-Arishi (1991) emphasize the importance of learner evaluation of process-oriented activities.

Written work can generally be completed under realized conditions (i.e., at home), but class time should be made available regularly for the planning of written tasks and feedback on any written work. Cohen (1991) concludes that "the students usually made only a mental note of the teacher's feedback" 
and suggests that a constructive strategy would be "the judicious use of revision, incorporating the teacher's comments" (p. 148). One means of achieving this is to make more class time available for reflection and revision.

\section{Conclusion}

In this article several strands of thought about learner processing time have been brought together and developed within a framework of classroom. dynamics. It has been argued that the greater use of time lapses, particularly in the form of deliberated and delayed silences, should be encouraged. Furthermore, more research should be conducted on different types of time lapses and their effects on classroom language learning and use.

\section{Acknowledgments}

I would very much like to thank the two editors of TESL Canada for their repeatedly constructive comments, their patience, and their encouragement in the drafting of this article.

\section{The Author}

Anthony Bruton has been at the University of Seville since 1981, before which he taught English and trained teachers in Brazil and Singapore. He has an MA in Applied Linguistics from Lancaster University and a PhD from the University of Seville. He is currently a lecturer in EFL methodology, and his main concern is developing the interface between theory and practice.

\section{References}

Carlsen, W.S. (1991). Questioning in classrooms: A sociolinguistic perspective. Review of Educational Research, 61, 157-178.

Catford, J.C., \& Pisoni, D.B. (1970). Auditory vs. articulatory training in exotic sounds. Modern Language Journal, 54, 477-481.

Chaudron, C. (1985a). Intake: On models and methods for discovering learners' processing of input. Studies in Second Language Acquisition, 7, 1-14.

Chaudron, C. (1985b). Comprehension, comprehensibility, and learning in the second language classroom. Studies in Second Language Acquisition, 7, 216-232.

Cohen, A. (1987). The use of verbal and imagery mnemonics in second-language vocabulary learning. Studies in Second Language Acquisition, 9, 43-62.

Cohen, A. (1991). Feedback on writing: The use of verbal report. Studies in Second Language Acquisition, 13, 133-159.

Cook, G. (1994). Repetition and learning by heart: An aspect of intimate discourse, and its implications. ELT Journal, 48, 133-141.

Crookes, G. (1989). Planning and interlanguage variation. Studies in Second Language Acquisition, 11, 367-383.

Dillon, J. T. (1988). Questioning and teaching. London: Croom Helm.

Dirven, R., \& Oakeshott-Taylor, J. (1984). Listening comprehension (part 1). Language Teaching, 17, 326-343.

Dirven, R., \& Oakeshott-Taylor, J. (1985). Listening comprehension (part 2). Language Teaching, $18,2-20$.

Ellis, R. (1987). Interlanguage variability in narrative discourse: Style shifting in the use of the past tense. Studies in Second Language Acquisition, 9, 12-20.

Holley, F.M., \& King, J.K. (1971). Imitation and correction in foreign language learning. Modern Language Journal, $58,494-498$. 
Murphy, J.M. (1989). Listening in a second language: Hermeneutics and inner speech. TESL Canada Journal, 6, 26-44.

Rowe, M.B. (1974). Pausing phenomena: Influence on the quality of instruction. Journal of Psycholinguistic Research, 3, 203-223.

Rowe, M.B. (1987). Using wait time to stimulate inquiry. In W.W. Wilen (Ed.), Questions, questioning techniques, and effective teaching (pp. 95-106). Washington, DC: NEA Professional Library.

Rutherford, W.E. (1987). Second language grammar: Learning and teaching. London: Longman.

Saville-Troike, M. (1988). Private speech: Evidence for second language learning strategies during the "silent" period. Journal of Child Language, 15, 567-590.

Shrum, J.L., \& Tech, V. (1985). Wait-time and the use of target and native languages. Foreign Language Annals, 18, 304-313.

Skehan, P. (1993). A framework for the implementation of task-based learning. IATEFL Annual Conference Report: Plenaries, 17-25.

Swain, M. (1985). Communicative competence: Some roles of comprehensible input and comprehensible output in its development. In S.M. Gass \& C.G. Madden (Eds.), Input and second language acquisition (pp. 235-253). Rowley, MA: Newbury House.

Tarvin, W.L., \& Al-Arishi, A.Y. (1991). Rethinking communicative language teaching: Reflection and the EFL classroom. TESOL Quarterly, 25, 9-27.

Terrell, T.D. (1986). Acquisition in the Natural Approach: The binding/ access framework. The Modern Language Journal, 70, 213-227.

van Lier, L. (1988). The classroom and the language learner. London: Longman.

White, J., \& Lightbown, P.M. (1984). Asking and answering in ESL classes. Canadian Modern Language Review, 40, 228-244.

Willis, D. (1990). The lexical syllabus. London: Harper Collins. 